\title{
Refrigeration System Performance by Inserting Twisted Strip in Condenser Along With Liquid Suction Heat Exchanger
}

\author{
T. Srinivasa Rao, K. Dilipkumar, K. Appa Rao
}

\begin{abstract}
This paper gives preliminary aftereffects of VCR (Vapor Compression Refrigeration) go through setting twisted strip inside the condenser tube, using liquid suction warmth exchanger (lshe), and $R 134 a$ as refrigerant in this cycle. examination executed on basic condenser tube with 3 different bended point strips verified in condenser tubes on the element of liquid suction heat exchanger for subcooling to remove suitable COP from cutting edge VCR machine. inside the proposed, lshe are taken through using each the procedures, strip focuses, $\alpha=a$ hundred,one hundred forty \&one hundred eighty by methods for undeniable chamber and with subcooling. The proposed check has additionally made a through and through appraisal of COP, refrigeration influence, charge of impact and capability. in the communicated test; it's miles put that the drop in weight is $16 \%$ for the twisted strip tube condenser while in evaluation to customary condenser tube. other than it's in like manner seen that condenser with bowed strip implanted increments quick rot inside the temperature of evaporator than basic chamber. The effect and viability of misshaped strip verified cylinder condenser is unnecessary as strain drop falls in the condenser and decline of evaporator temperature.
\end{abstract}

Key articulations:-COP, VCR, Liquid suction heat exchanger.

\section{ORDER:}

COP coefficient of execution, dimensionless

CP particular warmness of water, $\mathrm{kj} \mathrm{kg}-1$ attractive 1

DT alternate in water temperature, $0 \mathrm{C}$

Dt time logged like dT

$\mathrm{H}$ unique enthalpy , $\mathrm{J} \mathrm{kg-1}$

identity inner broadness, $\mathrm{mm}$

Lshe liquid suction warmth exchanger

M mass of the water, $\mathrm{kg}$

OD outer broadness, $\mathrm{mm}$

$\mathrm{Q}$ refrigeration influence, $\mathrm{kj}$

VCR vapour weight refrigeration

$\alpha \quad$ twisted strip mien, affirmation

I. creation

Incredible estimated examinations are done on VCR structure coming about on account of its huge grouping of ventures. Lshe is contracted in VCR cycle that permits the drop of commonness of vapor refrigerant by methods for sub cooling which leads the improvement of coefficient of execution of the cycle. Superheating, Subcooling and development of nano particles are different fruitful methodologies brought for better as a rule execution of

Revised Manuscript Received on April 12, 2019.

T. SrinivasaRao,Professor, Department of Mechanical Engineering, VVIT, Nambur, India. (sr.tanneeru@gmail.com)

K.Dilipkumar,Professor, Department of Mechanical Engineering, LBRCE, Mylavaram, India.(dilip_011@yahoo.co.in)

K. AppaRao, Professor, Department of Mechanical Engineering,LBRCE, Mylavaram, India. (Iapparaokandimalla@gmail.com) refrigeration cycle. The contrasting above, lshe is one of the significant one's as it conveys clearly higher gem yield of the contraption by strategy for subcooling the refrigerant from condenser and superheating the refrigerant hovering into the blower. each must be done with the guide of using lshe at the same time. This warm temperature exchanger may similarly next to or won't have an effect at the general execution of the gadget it depends after working running conditions and places of refrigerant. the ebb and flow exploratory research fuses each liquid suction warm temperature exchanger and wound strip implanted into condenser tubes in VCR machine.

Domanskiet.Al (1994) speculatively evaluated the general execution of lshe and concentrated the thermodynamic running working conditions and fluid homes of refrigerant required for the overhaul in the general execution of the structure wherein going for walks weight is unaltered and cooling limit is severa. They decided numerical method among COP, evaporator capacity, blower masterpiece, volumetric limit with regards to both liquid suction heat exchanger and up-to-date VCR cycle. This look at have ended up being endured for 29 obvious refrigerants. They assumed that there is an improvement in COP and volumetric limit of changed cycle diverged from standard cycle. Refrigerants with low all in all execution in ordinary cycle benefit by liquid suction warmth exchanger.

S.A.Kleinet.Al (2000) works on exchange quality among refrigerant coming to impact valve and refrigerant going to blower. Refrigerants R507A, R134a, R12, R404A, R290, $\mathrm{R} 407 \mathrm{c}, \mathrm{R} 600$ and R410A are used on this view. They inspected the effect of strain drop in liquid suction warmth exchanger on the display of device and unremarkable that liquid suction warmness exchangers are invaluable at high temperature lifts and for refrigerants having really little valve of $\Delta \mathrm{hvap} /(\mathrm{Cp} \mathrm{L} \mathrm{Tc})$.

Christian J.L.Hermes (2013) played out an experimentation on liquid suction warmness exchanger with the refrigerants R134a, R22, R290, R410A\& R717 used in VCR system. The refrigerants having horrendous regular introduction on vital VCR machine gets advantage from changed VCR contraption i.E. VCR device with liquid suction heat exchanger COP of the used refrigerant may likewise or might not empowered in any case relies on lethargic warmness, warmth exchanger ampleness and working weight. They derived that COP extra for R134a, R290, and R410A and R600a refrigerants.

Published By:

Blue Eyes Intelligence Engineering 


\section{Refrigeration System Performance By Inserting Twisted Strip In Condenser Along With Liquid Suction Heat Exchanger}

Md.RezaSalimpouret.Al (2014) thought about the general all around execution of the Vapor weight refrigeration system with condenser contained through wound rope installed strips continue running with refrigerant R404A. An examination accomplished on number one chamber and five circled rope implanted chambers . The injury rope engages in warmth switch grow and weight drop that results in redesign inside the device execution. It changed into gathered that there may be an impact inside the weight fall by methods for one hundred and twenty $\%$ stood out from fundamental chamber and besides contemplated that as hurl of circled wire decreases, the weight drop is extra.

\section{EXPERIMENTAL SETUP}

The image point of view on the preliminary setup is spoken to in fig-1, the found cycles are portrayed on the strain enthalpy diagram showed up in fig-2.The machine joins float lines one with liquid suction warm temperature exchanger and particular line is without liquid suction warm temperature exchanger. 4 shell and chamber condensers are created with and without strip implanted. The copper compartment of ID is $10 \mathrm{~mm}$, OD is $12 \mathrm{~mm}$ are worn to make the condenser of length $3 \mathrm{~m}$ inside the condition of a restrict with seven passes. The strips are bowed with the benefit of an edge of a hundred,a hundred and forty \&a hundred and eighty slight steel sheet of thickness $0.4 \mathrm{~mm}$ is used for the strips. the ones strips are installed in each condenser tube. This show is closed in a shell created utilizing tin sheet of period is equal to $52 \mathrm{~cm}$. A fan is set up to blow air quickly to the chambers. There are control valves at each condenser inlet and outlet to supervise the definite condenser.

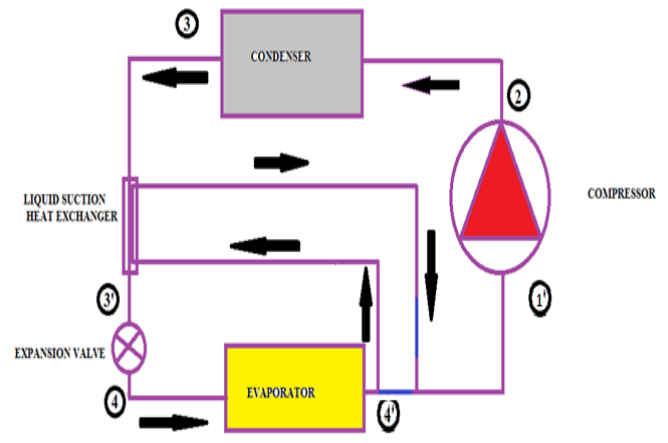

Fig. 1. Schematic representation of the VCR system with Liquid suction heat exchanger

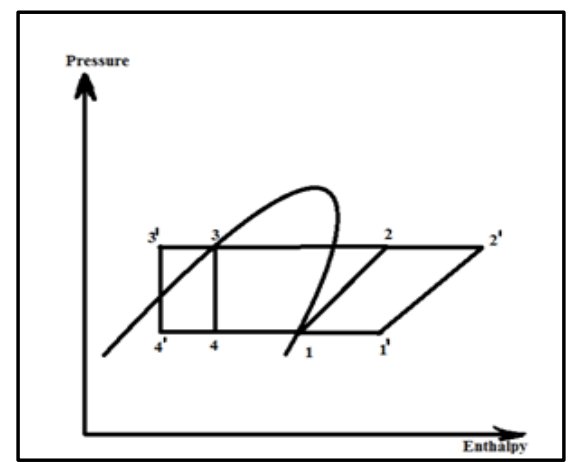

Fig. 2. Pressure enthalpy diagram

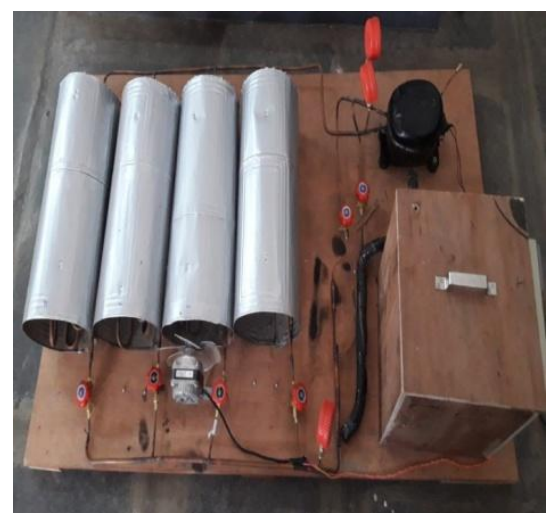

Fig. 3:Experimental set up of the VCR system test rig.

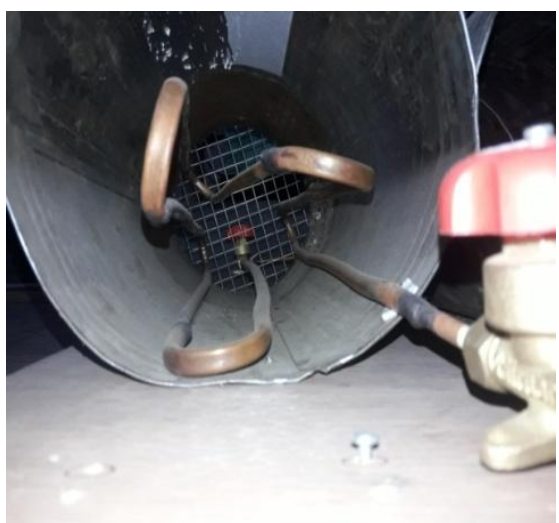

Fig. 4: Condensers tubes are placed in the shell

The liquid suction warmth exchanger is product of copper cubicles of $\mathrm{OD}=12 \mathrm{~mm}$, identity $=10 \mathrm{~mm}$ and $\mathrm{OD}=6 \mathrm{~mm}$, identity $=4 \mathrm{~mm}$ copper tubes. It's miles a chamber in chamber (twofold pipe) warmness exchanger with parallel flow and period 200mm. In $\mathrm{OD}=6 \mathrm{~mm}$ tube refrigerant from condenser will streams and in $12 \mathrm{~mm}$ chamber refrigerant drawing closer from evaporator streams. There are valves to paintings liquid suction warmness exchanger.

Refrigerant out and out weight is correct by weight tests arranged at three zones at delta and outlet of condenser, cove of blower with precision of zero.1psi.Temperature of refrigerant is method beneath control and outlet of condenser. Leaving refrigerant from condenser is chilled down to sub-cooled liquid the usage of liquid suction warmness exchanger.

The number one and completing temperatures of water are précised through using adequate-type thermocouples with a precision of $\pm 10 \mathrm{C}$. The water is sited in evaporator can as warm temperature load. Inside the unique chamber evaporator, refrigerant streams over the sort of chamber and water is out of doors the chambers. To lower the glow disaster, the chamber is all around secured. The essentialness eaten up via gadget is resolved from voltage and current.

Within the beginning exam turned into completed without liquid suction warmth exchanger on 4 condensers (no strip, $\alpha=100,140 \& 100$ and 80 ).Every condenser is opened or closed through valves gave at bay and outlet of condenser. At the length of examination simplest a solitary condenser is

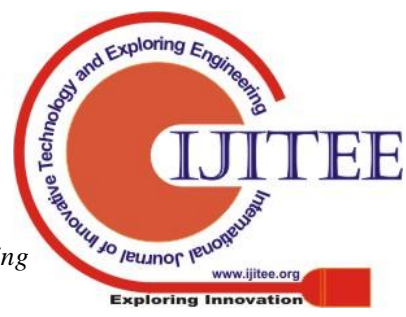


opened, remaining had been closed. Later examinations are finished through making use of liquid suction warm temperature exchanger, on liquid line of the VCR machine to locate its final results at the COP of the structure.

\section{Areas AND EQUATIONS}

The take a look at effects on VCR without liquid suction warmth exchanger and strips are used as a form of factor of view for this examination. In the gift experimentation refrigeration sway, refrigeration functionality and drop in weight during over condenser is resolved and people parameters are required to parent $\mathrm{COP}$ of the tool. Conditions I and ii are being implemented for the calculation of COP of vapor weight shape and warmth held from water. The refrigerating impact and COP of the form were resolved as seeks after.

$\mathrm{COP}=\frac{\text { Refrigeration effect }}{\text { Compressor power }}$

$$
\mathrm{Q}=\mathrm{m} \mathrm{C}_{\mathrm{p}} \frac{d T}{d t}
$$

Where,

$$
\begin{aligned}
& \mathrm{Q} \text { - Refrigeration effect } \\
& \mathrm{m} \text { - Mass of the water } \\
& \mathrm{dT} \text { - Change in water temperature } \\
& \mathrm{C}_{\mathrm{p}} \text { - Specific heat of water } \\
& \mathrm{dt} \text { - Time logged corresponding to dT }
\end{aligned}
$$

\section{RESULTS AND DISCUSSION}

Experimentation was accomplished on only one condenser where all other condensers are closed via control valves and also underneath sub-cooling and with out subcooling at regular cooling load (i.E.7 liters water) in evaporator.

Impact OF TWISTED STRIP INSERTED CONDENSER WITH AND with out making use of LIQUID SUCTION warmth EXCHANGER

Due to drop in strain throughout condenser with growing the twist perspective of the strip consequences in improving refrigeration impact.

Fig -5 represents decrement in water temperature with increase in twist attitude for the four condensers. At a hundred and eighty twist strip condenser higher in cooling effect was found without applying lshe.

Utility of 1she shows development in cooling overall performance. Observe has shown that characteristic of lshe reduces the temperature of refrigerant and improves the cooling capability within the evaporator. Cooling ability complements with the aid of increasing drop in temperature of water changed into identified.

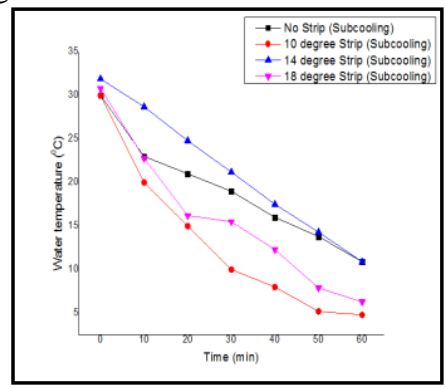

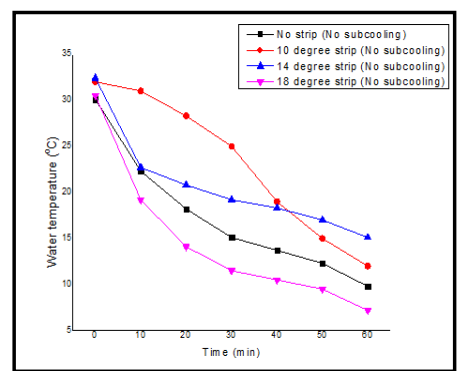

Fig. 5: Effect of strip inserts on water temperature with and without Subcooling effect of twisted strip inserted condenser on refrigerating effect

Fig-6 addresses effect of turned strip inserted condenser on refrigerating effect. It advanced toward getting to be arranged that refrigeration sway increases for wound strip inserted condenser than certain chamber condenser. Subcooling through lshe has colossal effect on refrigeration sway. The refrigeration impact augments as packages as 100 and eighty strip inserted condenser in no subcooling condition and underneath subcooling refrigeration impact is most prominent for 100 strip installed condenser. due to extra arrangement in weight the dissemination system impacts. it is furthermore settled that the temperature of refrigerant out of lshe coming to condenser and refrigerant streams into lshe from outlet of evaporator is thin. Along these lines, refrigeration effect diminishes on progress of time. Additionally, the temperature of the refrigerant after condenser is better than refrigerant temperature after lshe (early than improvement valve) best 2 to 30C.this is on creating strip perspective the general execution of lshe lessens so the refrigerating effect diminishes in subcooling circumstance anyway the standard all things considered execution of lshe is more conspicuous than execution of VCR device without subcooling.

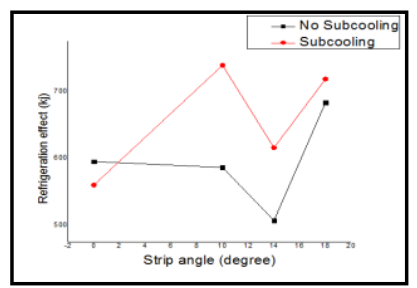

Fig. 6. Effect of refrigeration effect on the VCR system with strips inserted condenser

\section{EFFECT OF TWISTED STRIPS ON REFRIGERATION EFFICIENCY}

By the application of twisted strips inserted condenser have increased the cooling effect capacity.Figure-7 shows relationship between strip angles and improvement in refrigeration efficiency for $\mathrm{R} 134 \mathrm{a}$ refrigerant with and without lshe. When subcooling is applied between condenser and expansion valve i.e., capillary tube of VCR system, refrigeration efficiency has improved. Maximum refrigeration efficiency is obtained at $10^{\circ}$ strip inserted condenser for subcooling condition. 


\section{Exchanger}

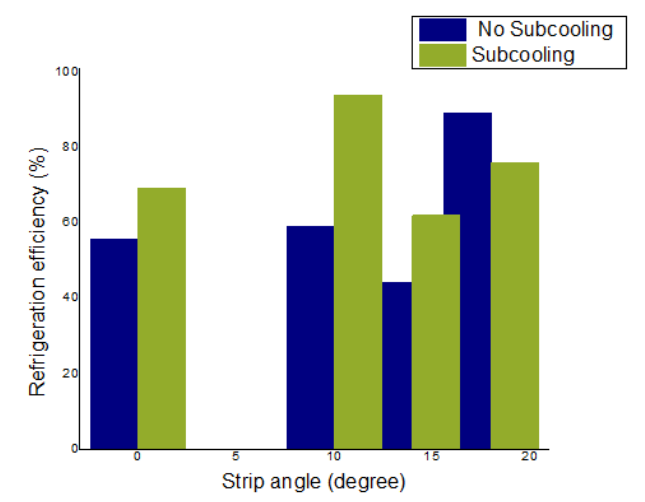

Fig. 7: Effect of strip inserts on increase in COP

\section{CONCLUSIONS}

In this exam of VCR form with became strips implanted condenser and lshe on liquid line improves the introduction parameters of VCR system.

The COP changed into evaluated for all of the four condensers with simple chamber, a hundred, one hundred forty and 100 and 80 set up strips, with outlshe and lshe associated with liquid line.COP prolonged with the aid of growing damage strip element from no strip to a hundred and 80 twisted strip condensers with out applying lshe. For one hundred and 80 strip part augments in COP of the shape as an awful lot as $12.87 \%$. With lshe the COP is extended up to a hundred strip factor and the development in COP as a lot as $24.206 \%$.

- The execution of the form is influenced via drop in weight over the condenser. In case the burden drop is excessive the COP lessens. The recognized weight drop is spherical seventy five psi.

- The refrigeration performance is most super at 100 strip with subcoolingand than without subcooling the refrigeration capability prolonged as much as $52.812 \%$ than direct VCR structure.

\section{REFERENCES}

1. strain drop and warmth trade courting for each microfin cylinder and wound tape implants in laminar move. S. AlFahed, L.M. Chamra, W. Chakroun, Experimental Thermal and Fluid technological information 18 (1999) 323-333.

2. Refrigeration form execution the usage of liquid suction warm temperature exchangers, S.A. Klein , D.T. Reindl, k. Brownell, international magazine of Refrigeration 23 (2000) 588-596.

3. Arrange flow schedules in spherical, rectangular and rectangular chambers within the midst of improvement of refrigerant R134a,John W. Coleman, SrinivasGarimella,global journal of Refrigeration 26 (2003) 117-128.

4. A graph for predicting the possible favored characteristic of greedy a suction/liquid warmth exchanger in refrigerating form ,R. Mastrullo, A.W. Mauro, S. Tino, G.P. Vanoli, completed Thermal Engineering 27 (2007) 2443-2448.

5. Experimental recollect on improvement warmth bypass in vertical minichannels for new refrigerant R1234ze(E) as opposed to R134a and R236fa, J.E. Park, F. Vakili-Farahani, L. Consolini, J.R. Thome, Experimental Thermal and Fluid technology 35 (2011) 442-454.

6. Augmentation of laminar circulate and heat drift in level chambers with the aid of using strategies for helical screwtape installs, E.Z. Ibrahim, electricity Conversion and manage fifty(2011) 250-257.
7. Experimental evaluation of weight drop in spherical chambers gave physical disconnected, diverse, short-length bended tapes, P. Ferroni, R.E. Square, N.E. Todreas, A.E. Bergles, Experismental Thermal and Fluid technological know-how 35 (2011) 1357-1369.

8. Warm temperature alternate development and weight drop of the quantity concentric chamber with bended wires brush installs, PaisarnNaphon, TanaponSuchana, worldwide Communications in warmth and Mass transfer 38 (2011) 236241.

9. Effect of punctured twisted tapes with parallel wings on warmth float update in a glow exchanger tube, C. Thianponga, P. Eiamsa-arda, P. Promvongea, S. Eiamsa-ardb, electricity Procedia 14 (2012) 1117 - 1123.

10. Oportunity evaluation of liquid to-suction warmth trade the refrigeration cycle, Christian J.L. Hermes, global journal of refrigeration 36 (2013)2119-2127.

11. Enhancement of COP in Vapor Compression Refrigeration machine. Krishna Prasanna,P.S. Kishore, international mag of Engineering research and era (IJERT), ISSN: 2278-0181, Vol. 3 problem eleven, November-2014.

12. Enhance the cop of Vapor weight cycle with trade in Evaporator and Condenser weight, Shoyabhussan, worldwide magazine of scientific and Engineering research, quantity 6 , hassle five, can also-2015 ISSN 2229-5518.

13. Overall performance Enhancement of Refrigeration Cycle by means of employing a heat Exchanger, Shoeb J. Inamdar, H.S. Farkade, global magazine of Engineering studies And advanced technology(IJERAT) ISSN: 2454-6135 [Volume. 02 Issue.11, November-2016]. 